\title{
Effect of tamoxifen alone and in combination with RU 486 on the endometrium in the mid-luteal phase
}

\author{
M.-L.Swahn, M.Bygdeman ${ }^{1}$, M.Seppälä², \\ E.Johannisson ${ }^{3}$ and S.Cekan \\ Department of Obstetrics and Gynaecology, Karolinska Hospital, \\ S-104 01 Stockholm, Sweden, ${ }^{2}$ Department I of Obstetrics and \\ Gynaecology, University Central Hospital, Helsinki, Finland and \\ ${ }^{3}$ Hôpital Cantonal, Geneva, Switzerland \\ ${ }^{1}$ To whom correspondence should be addressed
}

The effects of RU 486 combined with tamoxifen and tamoxifen alone on hormonal parameters and endometrial development at the time of implantation were studied. Measurements of cytosolic oestrogen and progesterone receptors in endometrium and placental protein 14 (PP14) in plasma were also included. Three dosage schedules were used: single oral dose of $40 \mathrm{mg}$ tamoxifen alone and in combination with $200 \mathrm{mg}$ RU 486, and $40 \mathrm{mg}$ tamoxifen for three consecutive days starting on the first day after the luteinizing hormone (LH) surge. The combined treatment prolonged the luteal phase $(P<0.05)$ and increased the plasma levels of progesterone. A single dose of tamoxifen did not affect the bleeding pattern and plasma hormone levels, but raised plasma oestradiol and LH with the 3-day treatment. The endometrium was retarded after the combined and the 3-day treatment with tamoxifen. Concentrations of cytosolic progesterone receptors were higher after the combined therapy, but were unaffected after tamoxifen only. PP14 levels were higher $(P<0.05)$ after repeated tamoxifen doses than in controls, but were lower with combined treatment. Progesterone and oestrogen are evidently necessary for endometrial maturation during the secretory phase of the menstrual cycle. PP14 levels in plasma cannot be used for clinical assessments of endometrial function because high levels coincide with disturbed endometrial development.

Key words: menstrual cycle/PP14/RU 486/steroid hormone receptors/tamoxifen

\section{Introduction}

Ovarian steroids are responsible for the development of a normal endometrium during different phases of the menstrual cycle. Oestradiol is essential for the synthesis of the progesterone receptor, and progesterone down-regulates both the oestradiol and the progesterone receptors (Jänne et al., 1975; Tseng and Gurpide, 1975; Kreitmann et al., 1979). Hence, treatment with receptor blockers might interfere with the regulation of the menstrual cycle by affecting both the hormonal balance and endometrial development. In normally cycling women, treatment with the progesterone receptor blocker RU 486 (Roussel, Uclaf, Paris, France) in mid- to late luteal phase induces uterine bleeding, followed in some women by a second bleeding at the time of the expected menstruation. The underlying mechanism is mainly a local effect on the endometrium (Hermann et al., 1985; Schaison et al., 1985; Swahn et al., 1988). A marked retardation of endometrial development was noticed up to at least 4 days after a single dose of $200 \mathrm{mg}$ RU 486 administered on the second day after the luteinzing hormone (LH) peak without affecting the bleeding or hormonal pattern of the cycle (Swahn et al., 1990). On the other hand, treatment of women with $40 \mathrm{mg}$ daily of the oestrogen receptor blocker, tamoxifen (ICI, Macclesfield, UK), over the entire luteal phase markedly increased the level of ovarian hormones (Swahn et al., 1989) during the treatment period and also during the subsequent cycle, whereas the cycle length was only marginally affected. In contrast, short-term treatment in the early luteal phase in primates both prolonged the cycle and decreased the fertility rates (Ravindranath and Moudgal, 1987; Olive et al. , 1990) without affecting hormonal secretion, indicating local effects of tamoxifen on the endometrial development.

From studies on in-vitro fertilization (IVF) it appears that the window of endometrial receptivity in the human is restricted to $\sim 3$ days (Navot et al., 1991). It is therefore possible that compounds which interfere with endometrial maturation in the secretory phase may be developed into effective contraceptive methods. The aim of the present study was to evaluate the effect of tamoxifen and tamoxifen in combination with RU 486 on hormonal parameters, endometrial histology and the serum placental protein 14 (PP14) concentration around the time of implantation following administration of the compounds immediately after the LH surge.

\section{Materials and methods}

A total of 24 regularly menstruating healthy volunteers with a cycle length between 25 and 35 days for the last three cycles before admission were recruited for the trial. None of the women used an intra-uterine device (IUD) or oral contraceptive steroids. The study consisted of one control, one treatment and one posttreatment cycle. The volunteers were allocated to one of three treatment schedules: group I received $\mathbf{4 0} \mathrm{mg}$ tamoxifen as a single oral dose at 8.00 p.m. on the day after the urinary LH peak; group II was given $40 \mathrm{mg}$ tamoxifen daily for 3 days starting at the corresponding time of the cycle; and group III was given 
$40 \mathrm{mg}$ tamoxifen and $200 \mathrm{mg}$ RU 486 at 8.00 p.m. on cycle day LH +1 (single dose).

An endometrial biopsy was obtained from the fundal part of the uterus on day $\mathrm{LH}+7$ both in the control and in the treatment cycles. Part of the biopsy material was taken for morphometric analysis by light microscopy (Johannisson et al., 1987). The remaining material was snap frozen and studied for cytosolic, progesterone and oestrogen receptors using enzyme immunoassay (Abbott Laboratories, North Chicago, USA). In all patients urine samples from the first morning void were collected daily from day 7 of the cycle until the LH surge had been demonstrated in the control and treatment cycles. The appearance of the LH surge was identified using a dip-stick method (Ovukit, Monoclonal Antibodies, Inc., Sunnyvale, CA, USA) and verified by analysis of the morning urine samples by radioimmunoassay. Blood samples were drawn three times weekly from the day the dipstick urine analysis indicated appearance of the LH peak until menstruation in both cycles and analysed for $\mathrm{LH}$, progesterone, oestradiol and endometrial protein PP14. The pituitary and ovarian hormones were measured by radioimmunoassay using kits provided by the World Health Organization (WHO) Matched Programme (Sufi et al., 1988). Serum concentrations of PP14 were determined by radioimmunoassay (Seppälä et al., 1987). During the three cycles of the study, the subjects were asked to keep records on the duration and amount of vaginal bleeding and side-effects of the drug regimen. During the study period, the women were advised to use barrier methods for contraception.

The geometric mean and $95 \%$ confidence limits were calculated for the plasma levels of LH, ovarian steroids and PP14. Progesterone and oestradiol values were normalized around the day of the plasma LH surge. The area under the curve was calculated for the period from the $\mathrm{LH}$ peak to day $\mathrm{LH}+10$ for the ovarian hormones from day $\mathrm{LH}+3$ to day $\mathrm{LH}+10$ for LH in plasma using the summation of the trapezoidal areas between consecutive points. The area under the curve was used when comparing the hormonal levels. The PP14 levels were synchronized according to the first day of the following menstruation and the area under the curve was calculated for the last 10 days of the menstrual cycle including the first day of bleeding.

A log normal distribution was assumed for all hormonal and PP14 levels (Gaddum, 1945). For statistical calculations, paired $t$-test and two-way analysis of variance with appropriate contrasts were used, and a $P$-value $<0.05$ was considered statistically significant.

The study was approved by the Swedish Drug Regulatory Authorities and the Ethics Committee of the Karolinska Hospital.

\section{Results}

\section{Effects on cycle length}

The three treatment groups were similar with regard to age, weight, height, previous number of pregnancies and births. Table I illustrates the effect of different treatments on the duration of the menstrual cycle. The combination of a single dose of RU 486 and tamoxifen (group III) significantly prolonged the cycle $(P<0.05)$, from $27.9 \pm 3.0$ (mean \pm SD) in the control to $35.0 \pm 10.5$ days in the treatment cycle. However, in two subjects the treatment cycle was prolonged to 42 and 56 days respectively. After exclusion of these two subjects, the mean duration of control and treatment cycles for the remaining subjects was $27.0 \pm 2.8$ and $30.0 \pm 3.0$ days, respectively, this difference still being statistically significant $(P<0.05)$. Prolongation of the cycle was due to extension of the luteal phase from $12.6 \pm 1.8$ days in the control to $14.7 \pm 0.5$ days in the treatment cycle $(P<0.05)$. No effects were seen on the duration of the menstrual cycle by the two other treatment regimens. No other adverse reactions were registered by any of the participating women.

\section{Hormone levels}

Measurement of the LH surge in urine with the quick-test method and the radioimmunoassay gave similar results, while the plasma LH peak appeared slightly earlier (mean 0.53 days; range -1 to +2 ). In two subjects in treatment group II and in the two subjects in treatment group III with markedly extended treatment cycles, the discrepancy between plasma LH and that measured in urine was more pronounced. These four subjects were excluded from the statistical evaluation of hormone values. No differences were seen in the mean plasma levels of $\mathrm{LH}$, oestradiol and progesterone during the control cycles when the three treatment groups were compared (results not shown). After a single dose of tamoxifen (group I), the levels of ovarian hormones and $\mathrm{LH}$ did not differ from those of the control cycle. Treatment with tamoxifen for 3 days (group II) induced a significant increase in oestradiol levels $(P<0.01)$ (Figure 1), whereas progesterone

Table I. Mean ( \pm SD) duration of menstrual cycle in the control, the treatment and the post-treatment cycle when 40 mg tamoxifen as a single dose (group I), tamoxifen $40 \mathrm{mg}$ daily for 3 days (group II) and tamoxifen $40 \mathrm{mg}$ single dose plus RU $486200 \mathrm{mg}$ single dose (group III) were given or started (group II) in the evening of the luteinizing hormone (LH) surge +1

\begin{tabular}{|c|c|c|c|c|c|c|c|}
\hline & \multicolumn{7}{|c|}{ Days (mean $\pm \mathrm{SD}$ ) } \\
\hline & \multicolumn{3}{|l|}{ Control } & \multicolumn{3}{|l|}{ Treatment } & \multirow{2}{*}{$\frac{\text { Post-treatment }}{\text { Total }}$} \\
\hline & Proliferative & Luteal & Total & Proliferative & Luteal & Total & \\
\hline Group I $(n=8)$ & $14.2 \pm 2.2$ & $12.9 \pm 2.7$ & $27.1 \pm 3.1$ & $14.9 \pm 3.0$ & $13.4 \pm 1.5$ & $28.1 \pm 2.4$ & $27.4 \pm 3.4$ \\
\hline Group II $(n=8)$ & $15.7 \pm 3.5$ & $11.7 \pm 3.2$ & $27.5 \pm 3.2$ & $16.2 \pm 4.0$ & $13.7 \pm 2.3$ & $31.2 \pm 32.9$ & $27.7 \pm 2.2$ \\
\hline Group III $(n=8)$ & $15.7 \pm 2.6$ & $12.1 \pm 1.6^{*}$ & $27.9 \pm 3.0^{*}$ & $16.4 \pm 3.1$ & $18.6 \pm 8.1^{*}$ & $35.0 \pm 10.5^{*}$ & $31.4 \pm 8.4$ \\
\hline Group III $(n=6)^{\mathrm{a}}$ & $14.8 \pm 3.0$ & $12.6 \pm 1.8 *$ & $27.0 \pm 2.8^{*}$ & $15.3 \pm 2.7$ & $14.7 \pm 0.5^{*}$ & $30.0 \pm 3.0^{*}$ & \\
\hline
\end{tabular}

${ }^{\text {aT }}$ Two patients in whom the cycle length in the treatment cycle was prolonged to 42 and 56 days, respectively, have been excluded.

* Statistically significant difference between corresponding periods in the control and treatment cycles $(P<0.05)$. 
levels were unaffected (data not shown). LH levels were also significantly increased $(P<0.01)$ (Figure 1). After the combined therapy (group III), progesterone levels were slightly but significantly increased $(P<0.05)$, but the oestradiol (data not shown) and LH levels remained unaffected (Figure 2). Table II gives the area under the curve for plasma levels of progesterone, oestradiol and LH.

\section{Morphometric analysis}

The results of the morphometric analyses are summarized in Table III. For treatment group I, the day of the biopsy varied $<1$ day when related to the urinary and plasma LH surges, whereas in treatment groups II and III, the day of biopsy differed by $>3$ days in four subjects (two in each group) when related to the plasma LH surge.

Treatment with a single dose of tamoxifen (group I) had only a marginal effect on the endometrial development. A slight increase in the number of glands $(24.7 \pm 7.0$, versus
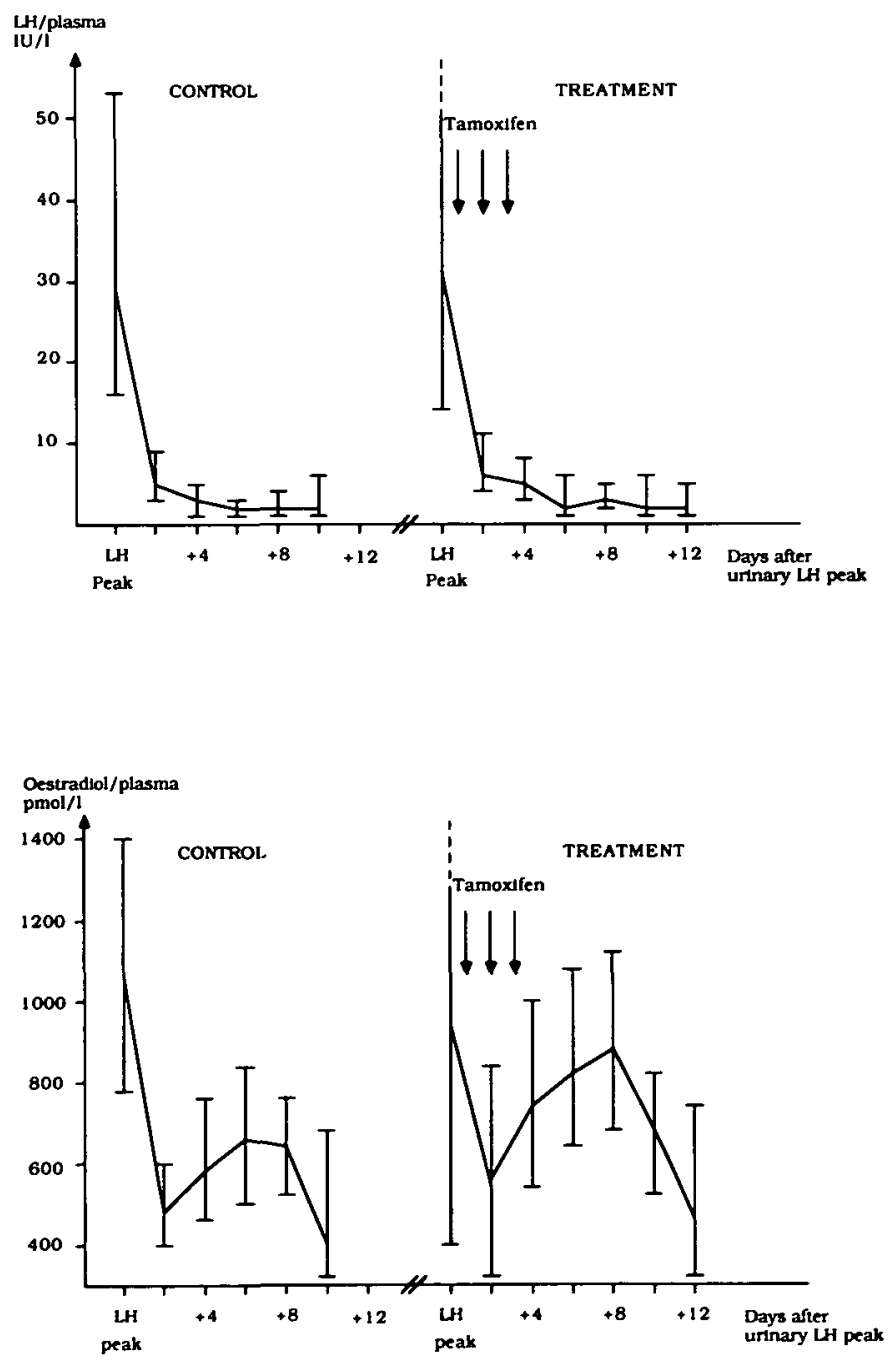

Fig. 1. Plasma levels of luteinizing hormone and oestradiol during control (group I) and treatment (group II) cycles after $40 \mathrm{mg}$ of tamoxifen from cycle day $\mathrm{LH}+1$ to +3 (geometric mean and $95 \%$ confidence limits) $(n=6)$. $\left.21.7 \pm 3.9 \mathrm{~mm}^{2}\right)(P<0.05)$ and a decrease of glandular epithelial height $(18.8 \pm 1.5$ versus $20.01 \pm 1.1 \mu \mathrm{m})$ $(P<0.05)$ were observed. Treatment with tamoxifen for 3 days (group II) considerably disturbed the endometrial morphology. In only one subject was the endometrial development considered in phase with the cycle, whereas irregular secretory activity or a retarded endometrium was demonstrated in the remaining subjects. In this group, statistical evaluation of the morphometric analysis revealed a significant increase in the number of vacuolated cells $\left(525\right.$ versus $69 / 10^{3}$ cells) $(P<0.01)$ and decreased glandular diameter $(83 \pm 21$ versus $102 \pm 13 \mu \mathrm{m})$ $(P<0.05)$. In treatment group III, the morphometric anlaysis was not conclusive in one subject in the treatment cycle. In the remaining subjects, irregular secretory activity or slight proliferation was noted in all but one subject, in whom the morphology was well in phase with the cycle. Again, statistical evaluation revealed increased numbers of glandular $(P<0.05)$ and stromal $(P<0.001)$ mitoses and a decrease in glandular diameter $(P<0.005)$ and glandular secretion $(P<0.01)$.
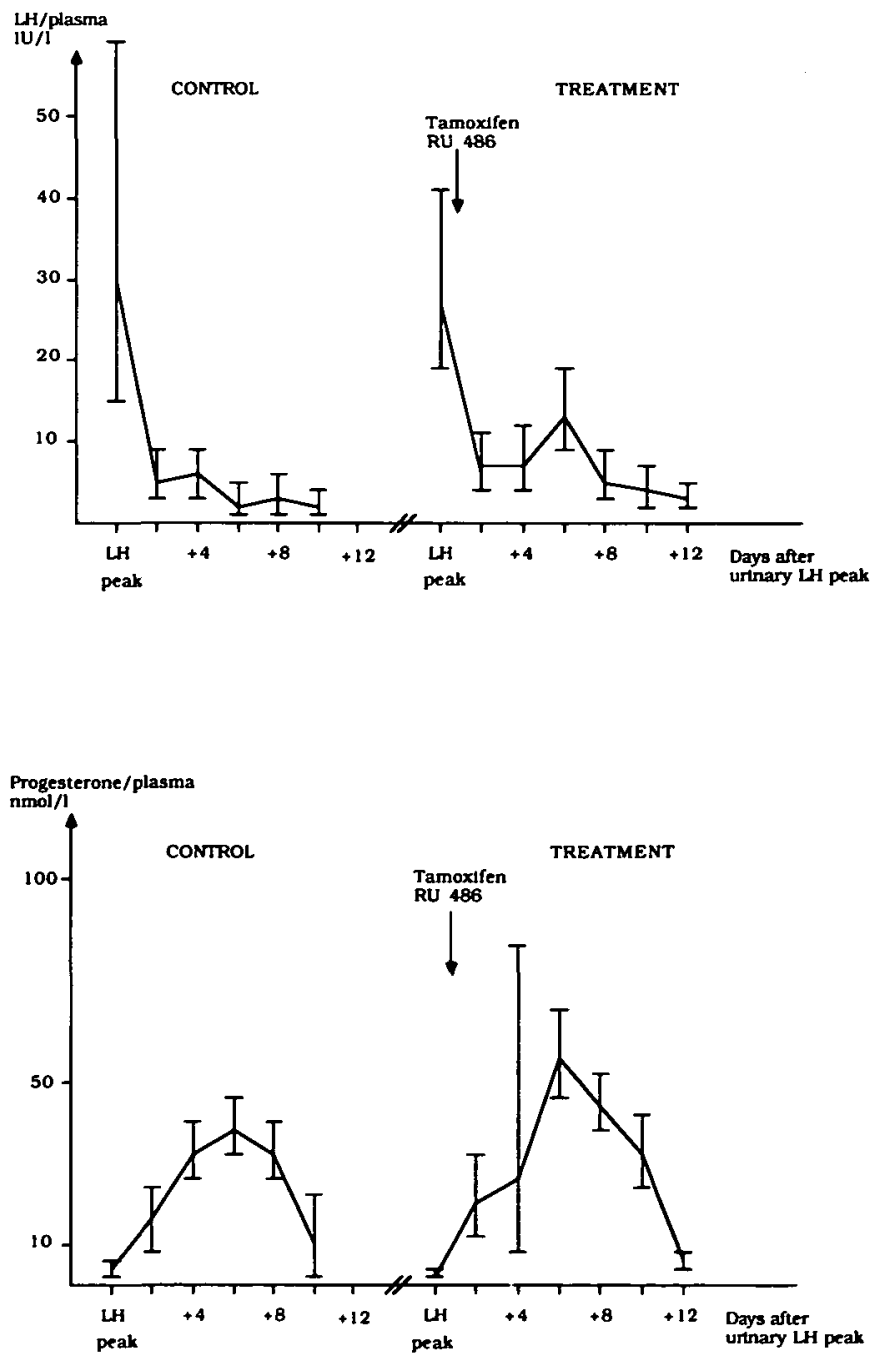

Fig. 2. Plasma levels of luteinizing hormone and progesterone in six subjects during control and treatment (group III) cycles after a single dose of $40 \mathrm{mg}$ tamoxifen and $200 \mathrm{mg}$ RU 486 (mifepristone) on cycle day $\mathrm{LH}+1$ (geometric mean and $95 \%$ confidence limits). 
Table H. Area under the curve for plasma levels of progesterone, oestradiol, luteinizing hormone (LH) and placental protein 14 (PP14) for the three treatment groups (specificed in Table I). The period calculated was day of the LH surge to LH +10 for progesterone and oestradiol; LH +3 to LH +10 for LH and the 10 last days of the cycle including the first day of bleeding for PP14

\begin{tabular}{|c|c|c|c|c|c|c|c|c|c|}
\hline & $\begin{array}{l}\text { Group I }(n=8) \\
\text { Control }\end{array}$ & $P$ & Treatment & $\begin{array}{l}\text { Group II }(n=6) \\
\text { Control }\end{array}$ & $P$ & Treatment & $\begin{array}{l}\text { Group III }(n=6) \\
\text { Control }\end{array}$ & $P$ & Treatment \\
\hline Progesterone & $\begin{array}{l}326 \\
(275-387)\end{array}$ & NS & $\begin{array}{l}316 \\
(259-386)\end{array}$ & $\begin{array}{l}288 \\
(198-419)\end{array}$ & NS & $\begin{array}{l}382 \\
(284-513)\end{array}$ & $\begin{array}{l}261 \\
(213-319)\end{array}$ & $<0.05$ & $\begin{array}{l}328 \\
(261-413)\end{array}$ \\
\hline Oestradiol & $\begin{array}{l}5668 \\
(5028-6389)\end{array}$ & NS & $\begin{array}{l}6273 \\
(5330-7383)\end{array}$ & $\begin{array}{l}6226 \\
(5084-7624)\end{array}$ & $<0.01$ & $\begin{array}{l}7919 \\
(6885-9109)\end{array}$ & $\begin{array}{l}6392 \\
(5173-7899)\end{array}$ & NS & $\begin{array}{l}6781 \\
(5336-8616)\end{array}$ \\
\hline LH & $\begin{array}{l}18.7 \\
(12.3-28.4)\end{array}$ & NS & $\begin{array}{l}22.7 \\
(16.2-31.8)\end{array}$ & $\begin{array}{l}18.6 \\
(13.3-26.0)\end{array}$ & $<0.01$ & $\begin{array}{l}29.8 \\
(20.4-43.6)\end{array}$ & $\begin{array}{l}30.9 \\
(17.7-53.8)\end{array}$ & NS & $\begin{array}{l}56.4 \\
(40.5-78.6)\end{array}$ \\
\hline PP14 & $\begin{array}{l}254 \\
(193-335)\end{array}$ & NS & $\begin{array}{l}309 \\
(238-402)\end{array}$ & $\begin{array}{l}251 \\
(179-352)\end{array}$ & $<0.05$ & $\begin{array}{l}445 \\
(179-711)\end{array}$ & $\begin{array}{l}230 \\
(148-360)\end{array}$ & $<0.01$ & $\begin{array}{l}171 \\
(124-234)\end{array}$ \\
\hline
\end{tabular}

NS $=$ not significant.

Data are of geometric mean and $95 \%$ confidence limits.

Table DI. Results of seven parameters assessed in the morphometric analysis of endometrial development when tamoxifen alone (groups I and II) or in combination with RU 486 (group III) was administered in the very early luteal phase

\begin{tabular}{|c|c|c|c|c|c|c|c|c|c|}
\hline & \multicolumn{3}{|l|}{$\begin{array}{l}\text { Group I } \\
(n=8)\end{array}$} & \multicolumn{3}{|l|}{$\begin{array}{l}\text { Group II } \\
(n=6)\end{array}$} & \multicolumn{3}{|l|}{$\begin{array}{l}\text { Group III } \\
(n=6) \\
\end{array}$} \\
\hline & Control & $P$ & Treatment & Control & $P$ & Treatment & Control & $P$ & Treatment \\
\hline No. of glands $/ \mathrm{mm}^{2}$ & $21.7 \pm 3.9$ & $<0.05$ & $24.7 \pm 7.0$ & $20.7 \pm 7.0$ & NS & $18.7 \pm 4.3$ & $22.9 \pm 6.5$ & NS & $19.6 \pm 7.8$ \\
\hline $\begin{array}{l}\text { No. of glandular mitoses/ } \\
10^{3} \text { cells }\end{array}$ & 0 & NS & 0 & 0 & NS & $2.0(0-12)$ & $0.7(0-4)$ & $<0.05$ & $6.2(0-13.4)$ \\
\hline $\begin{array}{l}\text { No. of stromal mitoses/ } \\
10^{3} \text { cells }\end{array}$ & $0.6(0-2)$ & NS & $0.2(0-0.5)$ & $0.7(0-3)$ & NS & $1.9(0-7.3)$ & $0.7(0-1.4)$ & $<0.001$ & $2.9(1.5-4.6)$ \\
\hline $\begin{array}{l}\text { No. of vacuolated cells/ } \\
10^{3} \text { cells }\end{array}$ & $21(0-100)$ & NS & $107(0-500)$ & $69(0-550)$ & $<0.01$ & $525(0-1000)$ & $271(0-850)$ & NS & $193(0-550)$ \\
\hline Glandular diameter $(\mu \mathrm{m})$ & $108 \pm 18$ & NS & $89 \pm 20$ & $102 \pm 13$ & $<0.05$ & $83 \pm 21$ & $100 \pm 11$ & $<0.005$ & $66 \pm 22$ \\
\hline $\begin{array}{l}\text { Glandular secretion } \\
\text { (score } 0-3 \text { ) }\end{array}$ & $2.5 \pm 0.6$ & NS & $1.8 \pm 0.5$ & $2.6 \pm 0.8$ & NS & $2.0 \pm 0.7$ & $2.3 \pm 0.7$ & $<0.01$ & $1.4 \pm 0.4$ \\
\hline $\begin{array}{l}\text { Glandular epithelial } \\
\text { height }(\mu \mathrm{m})\end{array}$ & $20.0 \pm 1.1$ & $<0.05$ & $18.8 \pm 1.5$ & $20.5 \pm 2.3$ & NS & $21.9 \pm 2.9$ & $20.2 \pm 2.9$ & NS & $20.2 \pm 2.6$ \\
\hline
\end{tabular}

Values given are mean (range) and mean \pm SD.

The specifications of the three treatment groups are given in Table I.

Table IV. Concentrations of progesterone and oestrogen receptors in endometrial biopsies on day of luteinizing hormone surge LH +7 in control and treatment cycles for the three treatment groups (specified in Table I)

\begin{tabular}{|c|c|c|c|c|c|c|}
\hline & \multicolumn{3}{|c|}{ Progesterone receptor (fmol/mg protein) } & \multicolumn{3}{|c|}{ Oestrogen receptor (fmol/mg protein) } \\
\hline & Control & $P$ & Treatment & Control & $P$ & Treatment \\
\hline Group I $(n=7)$ & $376(265-524)$ & NS & $433(313-599)$ & $59(40-89)$ & NS & $69(48-99)$ \\
\hline Group $\amalg(n=7)$ & $599(501-716)$ & NS & $643(380-1089)$ & $78(55-110)$ & NS & $74(47-117)$ \\
\hline Group $\mathrm{II}^{\mathrm{a}}(n=5)$ & $578(477-699)$ & NS & $469(352-624)$ & $81(55-119)$ & NS & $59(38-93)$ \\
\hline Group III $(n=6)$ & $595(410-863)$ & $<0.05$ & $912(715-1163)$ & $91(47-175)$ & NS & $148(102-216)$ \\
\hline Group $\Pi^{\mathrm{a}}(n=4)$ & $696(409-1182)$ & NS & $967(767-1219)$ & $122(51-289)$ & NS & $154(119-200)$ \\
\hline
\end{tabular}

${ }^{\text {a }}$ Two subjects with ovulatory disturbances in the treatment cycle are excluded.

Data are of geometric mean and $95 \%$ confidence limits.

\section{Steroid receptors}

The concentration of cytosolic progesterone and oestrogen receptors from a total of 20 subjects is shown in Table IV. The levels of progesterone and oestrogen receptors were unaffected by single or repeated doses (groups I and II) of tamoxifen, whereas the combined treatment (group III) increased the levels of progesterone receptors $(P<0.05)$. However, this elevation was not significant after exclusion of the two subjects with ovulatory disturbances in the treatment cycle.

\section{PP14}

The plasma levels of PPI4 were measured from the LH peak to the onset of menstruation. In control cycles, the PP14 concentration was $\sim 15 \mu \mathrm{g} / \mathrm{l}$ during the first week following the LH surge, but it increased steadily thereafter and reached $72 \pm 28 \mu \mathrm{g} / \mathrm{l}$ (mean $\pm \mathrm{SD}$ ) on the first day of menstruation (Figure 3A). After treatment with a single dose of tamoxifen (group I) the plasma levels of PP14 tended to be higher than during the control cycle but the difference was not significant 
A

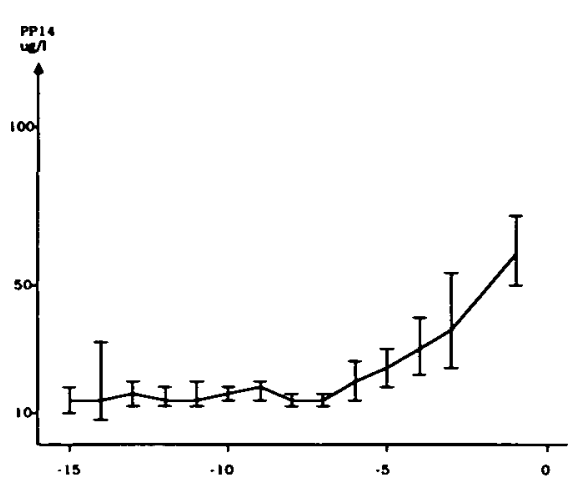

B

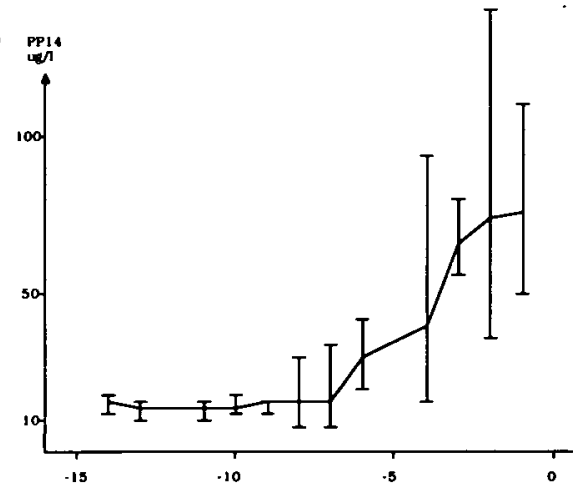

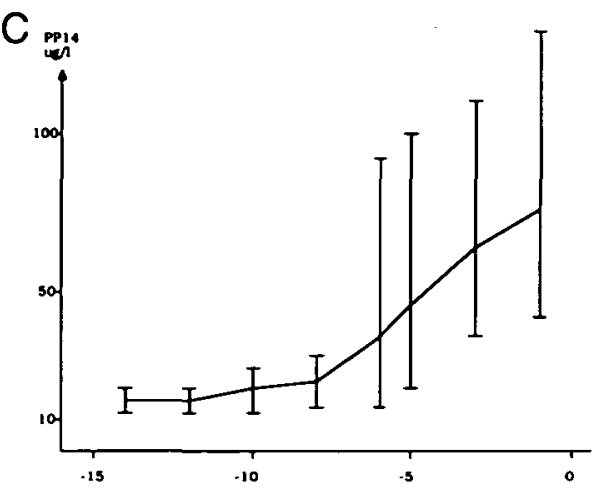

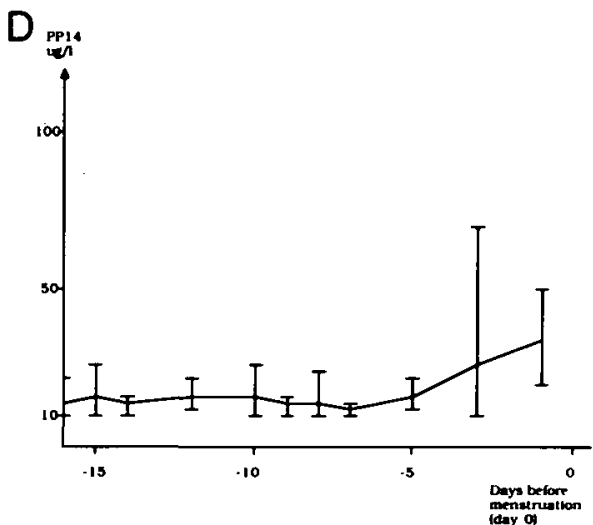

Fig. 3. Plasma levels of placental protein 14 (PP14) during control cycle (A), after a single dose of $40 \mathrm{mg}$ tamoxifen on cycle day LH +1 (B; group I, $n=8$ ), $40 \mathrm{mg}$ tamoxifen on cycle days $\mathrm{LH}+1$ to $\mathrm{LH}+3$ (C; group II, $n=6$ ) and a single dose of $40 \mathrm{mg}$ tamoxifen and $200 \mathrm{mg}$ mifepristone on cycle day LH +1 (D; group III, $n=6$ ) (geometric mean and $95 \%$ confidence limits). Day 0 refers to the first day of menstruation.

(Figure 3B). After 3 days' treatment with tamoxifen (group II) the levels were significantly higher $(P<0.05)$ than during the control cycle (Figure 3C). After the combined treatment (group III) the levels of PP14 were significantly lower $(P<0.01)$ than the control cycle (Figure 3D). This finding was also valid after exclusion of the two patients with prolonged cycles from the analysis of data (Table II).

\section{Discussion}

The aim of the present study was to evaluate the effects of antihormone treatment when administered early in the luteal phase. The patients received either a single oral dose of $40 \mathrm{mg}$ tamoxifen (group I), $40 \mathrm{mg}$ tamoxifen daily for 3 days (group II) or a combination of $40 \mathrm{mg}$ tamoxifen and $200 \mathrm{mg}$ RU 486 (group III). Tamoxifen is a derivative of triphenylethylene, which is supposed to act through binding to the oestrogen receptor. It is generally agreed that the antagonistic effect dominates over the oestrogenic action (Furr and Jordan, 1984). RU 486 similarly interacts with the progesterone receptor but has almost entirely antagonistic effects (Philibert $e$ t al., 1985). The half-life of both tamoxifen and RU 486 is long; for tamoxifen it is 7.5 days (Furr and Jordan, 1984) and for RU 486 detectable plasma levels have been demonstrated up to one week after a single oral dose of $200 \mathrm{mg}$ in most subjects (Swahn et al., 1990).
Bleeding pattern, hormone levels in blood and urine, endometrial development and concentration of oestrogen and progesterone receptors were monitored. Plasma hormone levels were measured three times a week and therefore, in some subjects, the concentration during the last day or two of the luteal phase was not available. Hormone levels were presented as the area under the curve during the time hormone levels were known for all patients. The treatment was invariably given at or started at $8.00 \mathrm{p} . \mathrm{m}$. on the first day after the urinary LH surge. In most cases the urinary LH surge detected by the quicktest method coincided with the plasma $\mathrm{LH}$ surge. As follicular rupture occurs within $24 \mathrm{~h}$ after the start of the plasma LH surge (Garcia et al., 1981), the treatment was initiated after rupture of the dominant follicle. In two patients in each of treatment groups II and III there was a significant discrepancy in the time between the plasma and urinary LH peaks. Since incorrect timing of the treatment was possible in these cases, and effects of antihormones are dependent on the timing of the treatment, these subjects were excluded when plasma levels of ovarian steroids were calculated.

A single dose of tamoxifen in contrast to 3 days' treatment did not affect the menstrual cycle or any of the parameters assessed. This may indicate that the role of oestrogen in the early stage of the luteal phase is less important than in later stages, but could also be due to the increase in total dose of tamoxifen administered. 
Both tamoxifen (Sgarlata et al., 1984) and RU 486 (DiMattina et al., 1987) inhibit progesterone production in human granulosa cells in vitro. However in the present study, a single dose of tamoxifen administered immediately after ovulation did not interfere with luteal function judged by progesterone levels in plasma. A similar finding has been made after treatment with RU 486 alone in the early luteal phase (Swahn et al., 1990). Even repeated treatment with tamoxifen was without effect in this respect, confirming the previous results of Sherman et al. (1979). The principal effect of tamoxifen and RU 486 given together was apparently a stimulation of the corpus luteum function. The plasma progesterone levels were elevated concomitantly with a prolongation of the luteal phase. Similar effects have also been reported after antigestagen and tamoxifen treatment alone in later stages of the luteal phase (Garzo et al., 1988; Swahn et al., 1988). The luteotrophic effect of the combined therapy may reflect the effects at hypothalamic - pituitary level, although mean $\mathrm{LH}$ levels were not increased. However, the increased levels of progesterone receptor concentration of the endometrium may have potentiated the effects of increased progesterone levels on the uterus, postponing endometrial desquamation.

It is now well established that the formation of progesterone and oestrogen receptors is regulated by ovarian steroid hormones. We measured the effect of the antihormones tamoxifen and RU 486 on the concentration of both oestrogen and progesterone receptors in the endometrium. When interpreting the results, we appreciate that tamoxifen has some steroid agonistic effects. Short-term therapy with tamoxifen reduces the cytosolic oestrogen receptor concentration in the endometrium, while the progesterone receptor concentration actually increases (Baulieu et al., 1981), effects that are consistent with both antagonistic and agonistic activities. Although RU 486 is regarded as an almost pure antigestagen, secretory changes have been described in the endometrium of post-menopausal women pre-treated with oestrogen alone (Gravanis et al., 1985).

In the present study, neither of the tamoxifen treatment schedules were found to induce durable effects on endometrial steroid receptor levels. However, the time elapsed from the end of treatment to biopsy may have been too long to reveal early transitory changes in receptor concentrations. Increased levels of total oestrogen receptors but lack of effect on progesterone receptors have recently been reported by Gorodeski et al. (1992) after a single dose of tamoxifen in mid-luteal phase. Differences in treatment timing may explain the divergence between our results and those of Gorodeski et al. (1992). Also, in the present study, only cytosolic receptors were analysed and unknown amounts of nuclear receptors may thus have escaped analysis.

The combined therapy with antigestagen and anti-oestrogen significantly increased progesterone receptor concentrations whereas oestrogen receptor concentration was only slightly, but not significantly, elevated. These findings are consistent with the antagonistic effects of RU 486. The previously reported transitory decrease in progesterone receptor concentrations following administration of RU 486 early in luteal phase (Swahn et al., 1990) may have reflected some agonistic effects of RU 486 due to insufficient gestagenic activity at this early stage of the luteal phase. The addition of the oestrogen receptor blocker in the present study may have increased the antagonistic potency of RU 486 on the endometrium and, in fact, anti-oestrogens have been reported to exert some secretory changes in proliferative endometrium (Birkenfeld et al., 1986).

The disturbance of endometrial maturation seen after repeated doses of tamoxifen could be attributed to either an influence on progesterone or oestrogen receptors by the anti-estrogen, or to the increased levels of oestradiol in plasma, or to both. Delayed maturation of luteal phase endometrium has been reported earlier, both following continuous treatment with tamoxifen during the whole cycle (Sherman et al., 1979) and also in the luteal phase (Fritz et al., 1987). The high number of vacuolated cells contradicts any major effects on progesterone receptor function as this is mainly a progesterone-mediated effect. Since tamoxifen has a long half-life (7.5 days), substantial amounts of tamoxifen would still have been present at the time of biopsy and, therefore, the influence of elevated oestradiol levels on endometrium is unlikely. A blockage of oestrogen receptors during undisturbed progesterone influence seems to be the probable explanation for the endometrial structure observed following tamoxifen therapy, i.e., small glands, persistence of basal vacuoles and an abnormal secretion. Thus, not only progesterone but also oestrogen is essential for the maturation of the endometrium during the secretory phase.

Following the effects of combined tamoxifen-RU 486 treatment clearly indicates that the development of secretory endometrium was inhibited. This was seen despite elevated levels of both progesterone receptor in the endometrium and progesterone in plasma indicating a persistent blockage of progesterone receptors by RU 486 on day $\mathrm{LH}+7$. It is noteworthy that if RU 486 administration starts in the mid-luteal phase, the therapy invariably results in bleeding (Swahn et al., 1988). On the other hand, if RU 486 is given immediately after ovulation, bleeding is only rarely induced in spite of the fact that RU 486 is still present in the circulation and its antagonistic effect can be demonstrated on day $\mathrm{LH}+7$ (Swahn et al., 1990). This finding indicates that some secretory development is a prerequisite for endometrial shedding and bleeding to be induced by RU 486. In spite of the receptor blockage seen on day $\mathrm{LH}+7$, an overtly normal menstruation followed. This indicates that the process is reversible. Reversible effects of RU 486 on glandular secretion and uteroglobin production of the endometrium of pseudopregnant rabbits have also been reported (Hegele-Hartung and Beier, 1986).

Endometrial protein PP14 is synthesized by endometrial secretory glands (Julkunen et al., 1990). The plasma concentration of PP14 shows cyclic variation, being maximal at the onset of menstruation (Julkunen et al., 1986). Due to this pattern of PP14 secretion in plasma in the present study, the plasma levels of PP14 were synchronized around the first day of the menstruation and the area under the curve calculated for the last 10 days of the cycle, the period when progesterone levels were elevated. RU 486 rather than tamoxifen decreased serum PP14 levels, a finding confirming the belief that progesterone elevates PP14. Following combined therapy, glandular diameter and secretion decreased. Perhaps as a direct cause of the decreased PP14 (Julkunen et al., 1990). Repeated tamoxifen 
treatment significantly elevated levels of PP14 associated with increased glandular secretion without concomitant increase in progesterone concentration. This indicates that not only progesterone but also oestrogen, or the balance between these two, is important for the production of PP14. PP14 may help to assess endometrial function at the end of the menstrual cycle (Fay et al., 1990), but the present study shows that PP14 concentrations are high when endometrial development is highly deranged.

It is concluded that a single dose of tamoxifen given in combination with RU 486 on day $\mathrm{LH}+1$ has a strong influence on endometrial development. It significantly depresses the production of endometrial protein PP14, leaving the plasma levels of oestradiol and LH unchanged, and causing a slight increase in progesterone during the secretory phase. It is not known whether these effects are sufficient to prevent implantation.

\section{Acknowledgements}

We are grateful to Astrid Häggblad for typing the manuscript and drawing the figures. This study was supported by the World Health Organization, Special Programme of Research, Development and Research Training in Human Reproduction, Geneva, Switzerland, and by the Academy of Finland and the Finnish Social Insurance Institution to (M.S.). RU 486 was kindly provided by Roussel Uclaf, Paris, France.

\section{References}

Baulieu,E.E., Mortel,N., Levy,C., Namer,M. and Robel,P. (1981) Estrogen and progesterone receptors and response to an antiestrogen of post-menopausal endometrial carcinoma and metastatic breast cancer. Excerpta Medica, 551, 234-249.

Birkenfeld,A., Navot,D., Levij,I.S., Laufer,N., Beier-Hellwig,K., Goecke,C., Schenker,J.G. and Beier,H.M. (1986) Advanced secretory changes in the proliferative human endometrial epithelium following clomiphene citrate treatment. Fertil. Steril., 45, 462-468.

DiMattina,M., Albertson,B.D., Tyson, V., Loriaux,D,L. and Falk,R.J. (1987) Effect of the antiprogestin RU 486 on human ovarian steroidogenesis. Fertil. Steril., 48, 229-233.

Fay,T.A., Jacobs,I.J., Teisner,B., Westergaard,J.G. and Grudzinskas,J.G. (1990) A biochemical test for the direct assessment of endometrial function: measurement of the major secretory endometrial protein PP14 in serum during menstruation in relation to ovulation and luteal function. Hum. Reprod., 5, 382-386.

Fritz,M.A., Westfahl,P.K. and Graham,R.L. (1987) The effect of luteal phase estrogen antagonism on endometrial development and luteal function in women. J. Clin. Endocrinol. Metab., 65, 1006-1013.

Furr,B.J.A. and Jordan,V.C. (1984) The pharmacology and clinical uses of tamoxifen. Pharmacol. Ther., 25, 127-205.

Gaddum,J. (1945) Lognormal distributions. Nature, 156, 463-466.

Garcia,J.E., Seegar Jones,G. and Wright,G.L. (1981) Prediction of the time of ovulation. Fertil. Steril., 36, 308-315.

Garzo,V.G., Liu,J., Ulmann,A., Baulieu,E.E. and Yen,S.S.C. (1988) Effects of an antiprogesterone (RU 486) on the hypothalamichypophyseal-ovarian-endometrial axis during the luteal phase of the menstrual cycle. J. Clin. Endocrinol. Metab., 66, 508-517.

Gorodeski,G., Beery,R., Lunenfeld,B. and Geier,A. (1992) Tamoxifen increases plasma estrogen-binding equivalents and has an estradiol agonistic effect on histologically normal premenopausal and postmenopausal endometrium. Fertil. Steril., 57, 320-327.

Gravanis,A., Schaison,G., George,M., Brux,J., de Satayaswaroop,P.G., Baulieu,E.E. and Robel,P. (1985) Endometrial and pituitary responses to the steroidal antiprogestin RU 486 in postmenopausal women. J. Clin. Endocrinol. Metab., 60, 156-163.

Hegele-Hartung,C. and Beier,H.M. (1986) Distribution of uteroglobin in the rabbit endometrium after treatment with an antiprogesterone (ZK 98,734): an immunocytochemical study. Hum. Reprod., 1, 497-505.

Hermann,W.L., Schindler,A.M., Wyss,R. and Bischof,P. (1985) Effects of the antiprogesterone RU 486 in early pregnancy and during the menstrual cycle. In Baulieu,E.E. and Segal,S.J. (eds), The Antiprogestin Steroid RU 486 and Human Fertility Control. Plenum Press, New York, pp. 179-198.

Johannisson,E., Landgren,B.-M., Rohr,H.P. and Diczfalusy,E. (1987) Endometrial morphology and peripheral hormone levels in women with regular menstrual cycles. Fertil. Steril., 48, 401-408.

Julkunen,M., Apter,D., Seppälä,M., Stenman,U.H. and Bohn,H. (1986) Serum levels of placental protein 14 reflect ovulation in nonconceptional menstrual cycles. Fertil. Steril., 45, 47-50.

Julkunen,M., Koistinen, R., Suikkari,A.-M., Seppälä,M. and Jänne,O.A. (1990) Identification by hybridization histochemistry of human endometrial cells expressing mRNAs encoding a uterine betalactoglobulin homologue and an insulin-like growth factor-binding protein-1. Mol. Endocrinol., 4, 700-707.

Jänne,O., Kontula,K., Luukkainen,T. and Vihko,R. (1975) Oestrogeninduced progesterone receptor in human uterus. J. Steroid Biochem., 6, 501-509.

Kreitmann,B., Bugat,R. and Bayard,F. (1979) Estrogen and progestin regulation of the progesterone receptor concentration in human endometrium. J. Clin. Endocrinol. Metab., 49, 926-929.

Navot,D., Scott,R.T., Droesch,K., Veeck,L.L., Liu,H.-C. and Rosenwaks,Z. (1991) The window of embryo transfer and the efficiency of human conception in vitro. Fertil. Steril., 55, 114-118.

Olive,D.L., Schultz,N., Riehl,R.M., Groff,T.R. and Schenken,R.S. (1990) Effects of tamoxifen on corpus luteum function and luteal phase length in cynomolgus monkeys. Fertil. Steril., 54, 333-338.

Philibert,D., Moguilewsky,M., Mary,I., Lecaque,D., Tournemine,C., Secclu,J. and Deraedt,R. (1985) Pharmacological profile of RU 486 in animals. In Baulieu,E.E. and Segal,S.J. (eds), The Antiprogestin Steroid RU 486 and Human Fertility Control. Plenum Press, New York, pp. $49-68$.

Ravindranath,N. and Moudgal,N.R. (1987) Use of tamoxifen, an antiestrogen, in establishing a need for estrogen in early pregnancy in the bonnet monkey (Macaca radiata). J. Reprod. Fertil., 81, $327-336$.

Schaison,G., George,M., Lestrat,M., Reinberg,A. and Baulieu,E.E. (1985) Effects of the antiprogesterone steroid RU 486 during midluteal phase in normal women. J. Clin. Endocrinol. Metab., 61, 484-489.

Seppälä,M., Rönnberg,L., Karonen,S.-L. and Kauppila,A. (1987) Micronized progesterone increases the circulating level of endometrial secretory PP14/beta-lactoglobulin homologue. Hum. Reprod., 2, $453-455$.

Sgarlata,C.S., Mikhail,G. and Hertelendy,F. (1984) Clomiphene and tamoxifen inhibit progesterone synthesis in granulosa cells: comparison with estradiol. Endocrinology, 114, 2032-2038.

Sherman,B.M., Chapler,F.K., Crickard,K. and Wycoff,D. (1979) Endocrine consequences of continuous antiestrogen therapy with Tamoxifen in premenopausal women. J. Clin. Invest., 64, 398-404.

Sufi,S.B., Donaldson,A. and Jeffcoate,S.L. (1988) Method Manual WHO Programme for the Provision of Matched Assay Reagents for the Radioimmunoassay of Hormones in Reproductive Physiology, 12th ed. Geneva, Switzerland.

Swahn,M.-L., Johannisson,E., Daniore,V., de la Torre,B. and Bygdeman,M. (1988) The effect of RU 486 administered during the proliferative and secretory phase of the cycle on the bleeding pattern, hormonal parameters and the endometrium. Hum. Reprod., 3, 
$915-921$

Swahn,M.-L., Bygdeman,M., Ma,S.A. and Wu,Z.Y. (1989) The effect of tamoxifen on the function and life-span of the corpus luteum and on subsequent ovarian function. Acta Endocrinol. (Copenh.), 121, $417-425$.

Swahn,M.-L., Bygdeman,M., Xing,S., Cekan,S., Masironi,B. and Johannisson,E. (1990) The effect of RU 486 administered during the early luteal phase on the bleeding pattern, hormonal parameters and endometrium. Hum. Reprod., 5, 402-408.

Tseng,L. and Gurpide,E. (1975) Effects of progestins on estradiol receptor levels in human endometrium. J. Clin. Endocrinol. Metab., 41, 402-404.

Received on January 2 1992; accepted on October 14, 1992 